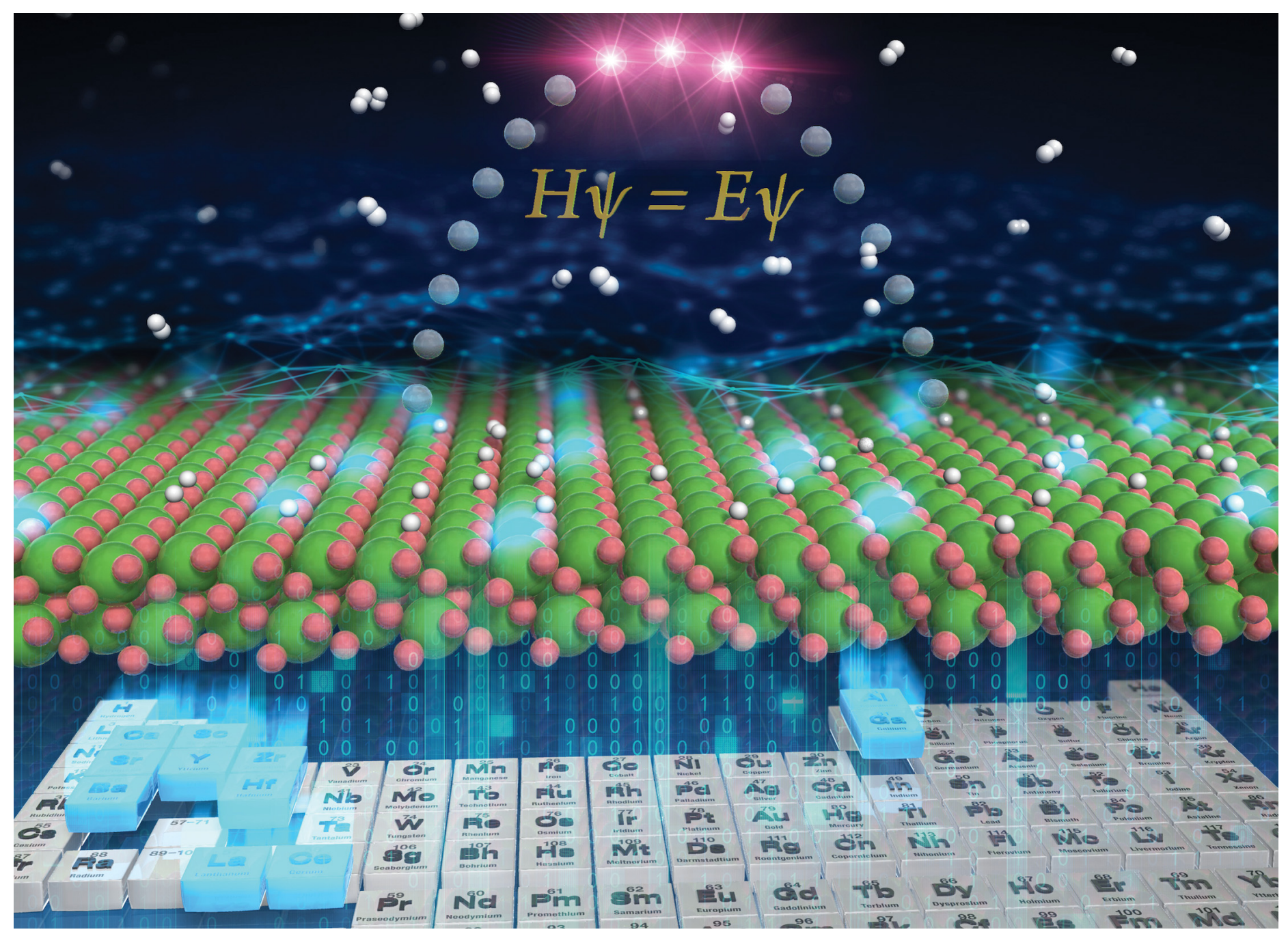

\section{Showcasing research from the Group of Prof. Yasushi Sekine at Waseda University, Japan.}

Theoretical prediction by DFT and experimental observation of heterocation-doping effects on hydrogen adsorption and migration over the $\mathrm{CeO}_{2}$ (111) surface

Hydrogen $(\mathrm{H})$ atom adsorption and migration over heterocation doped $\mathrm{CeO}_{2}$-based materials surface are investigated using density functional theory (DFT) calculations. Heterocations with smaller valence and smaller ionic radius induced the electron-deficient lattice oxygen, and the surface protonics is dominated by the $\mathrm{H}$ atom adsorption energy. $\mathrm{H}$ atom adsorption and migration over $\mathrm{CeO}_{2}$-based materials are important for catalytic reactions involving hydrogen subtraction and migration (hydrogen spillover and surface protonics) and also for electrochemical devices.

\section{As featured in:}

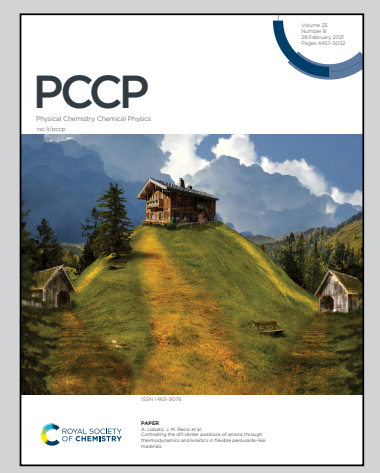

See Yasushi Sekine et al., Phys. Chem. Chem. Phys., 2021, 23, 4509 . 
Check for updates

Cite this: Phys. Chem. Chem. Phys.,

2021, 23, 4509

\title{
Theoretical prediction by DFT and experimental observation of heterocation-doping effects on hydrogen adsorption and migration over the $\mathrm{CeO}_{2}$ (111) surface $\dagger$
}

\author{
Kota Murakami, ${ }^{a}$ Yuta Mizutani, ${ }^{a}$ Hiroshi Sampei, ${ }^{a}$ Atsushi Ishikawa, (D) ${ }^{b}$ \\ Yuta Tanaka, ${ }^{a}$ Sasuga Hayashi, ${ }^{a}$ Sae Doi, ${ }^{a}$ Takuma Higo, (D) a Hideaki Tsuneki, ${ }^{a}$ \\ Hiromi Nakai iD ${ }^{c}$ and Yasushi Sekine iD *a
}

\begin{abstract}
Hydrogen $(\mathrm{H})$ atom adsorption and migration over the $\mathrm{CeO}_{2}$-based materials surface are of great importance because of its wide applications to catalytic reactions and electrochemical devices. Therefore, comprehensive knowledge for controlling the $\mathrm{H}$ atom adsorption and migration over $\mathrm{CeO}_{2}-$ based materials is crucially important. For controlling $\mathrm{H}$ atom adsorption and migration, we investigated irreducible divalent, trivalent, and quadrivalent heterocation-doping effects on $\mathrm{H}$ atom adsorption and migration over the $\mathrm{CeO}_{2}(111)$ surface using density functional theory (DFT) calculations. Results revealed that the electron-deficient lattice oxygen $\left(\mathrm{O}_{\text {lat }}\right)$ and the flexible $\mathrm{CeO}_{2}$ matrix played key roles in strong adsorption of $\mathrm{H}$ atoms. Heterocations with smaller valence and smaller ionic radius induced the electron-deficient $\mathrm{O}_{\text {lat. }}$ In addition, smaller cation doping enhanced the $\mathrm{CeO}_{2}$ matrix flexibility. Moreover, we confirmed the influence of $\mathrm{H}$ atom adsorption controlled by doping on surface proton migration (i.e. surface protonics) and catalytic reaction involving surface protonics $\left(\mathrm{NH}_{3}\right.$ synthesis in an electric field). Results confirmed clear correlation between $\mathrm{H}$ atom adsorption energy and surface protonics.
\end{abstract}

Received 4th November 2020

Accepted 17th January 2021

DOI: $10.1039 / \mathrm{d} 0 \mathrm{cp} 05752 \mathrm{e}$

rsc.li/pccp

\section{Introduction}

Hydrogen $(\mathrm{H})$ atom adsorption and migration over a metal oxide surface are fundamentally important for various catalytic reactions, as summarized in an earlier review. ${ }^{1}$ Many researchers have investigated passive migration of $\mathrm{H}$ atoms (i.e. hydrogen spillover) that are useful for hydrogenation and dehydrogenation of hydrocarbons, ${ }^{2-4} \mathrm{CO}_{2}$ reduction $^{5-7}$ and $\mathrm{NH}_{3}$ synthesis. ${ }^{8}$ Furthermore, most recently, we demonstrated novel lowtemperature catalysis involving $\mathrm{H}$ atom migration activated by an electric field, i.e. surface protonics. ${ }^{9-11}$ The electric field provokes the reaction through collision between $\mathrm{H}^{+}$over support and molecules (i.e. $\mathrm{N}_{2},{ }^{11-15}$ methylcyclohexane, ${ }^{16}$ and $\mathrm{CH}_{4}{ }^{17,18}$ ) over loading metals at the three-phase boundary (TPB). The $\mathrm{H}$ atom adsorption energy over metal oxides plays

\footnotetext{
${ }^{a}$ Applied Chemistry, Waseda University, 3-4-1, Okubo, Shinjuku, Tokyo 169-8555, Japan.E-mail: ysekine@waseda.jp

${ }^{b}$ National Institute for Materials Science, 1-1, Namiki, Tsukuba, Ibaraki 305-0044, Japan

'Chemistry and Biochemistry, Waseda University, 3-4-1, Okubo, Shinjuku, Tokyo 169-8555, Japan

$\dagger$ Electronic supplementary information (ESI) available. See DOI: 10.1039/ d0cp05752e
}

a fundamentally important role in catalytic reactions related to passive and electrochemically activated migration of $\mathrm{H}^{+}$. 8,13 Therefore, control of $\mathrm{H}$ atom adsorption over metal oxides is a central subject in the field of catalysts.

Doping of heterocations is a leading method among the methods that control metal oxide functions. Actually, $\mathrm{H}$ atom adsorption enhancement by doping has been reported for the cleavage of $\mathrm{H}-\mathrm{H}, \mathrm{C}-\mathrm{H}$, and $\mathrm{O}-\mathrm{H}$ bonds. ${ }^{19-23}$ Therefore, elucidation of the correlation between dopant features and $\mathrm{H}$ atoms adsorption is highly demanded for tuning catalytic reactions involving $\mathrm{H}$ atoms adsorption and migration.

As described herein, we examined the doping effects on $\mathrm{H}_{2}$ dissociative adsorption over the $\mathrm{CeO}_{2}$ surface using irreducible divalent, trivalent, and quadrivalent heterocations. $\mathrm{CeO}_{2}$-based materials have been used for various catalytic reactions ${ }^{24}$ including catalysis related to surface protonics in the electric field. ${ }^{15,17,18}$ Its utilization is not limited to catalysis. Many researchers have anticipated the usefulness of $\mathrm{CeO}_{2}$-based materials as an electrolyte. ${ }^{25-27}$ Therefore, comprehensive understanding of $\mathrm{H}$ atom adsorption over $\mathrm{CeO}_{2}$-based materials is needed. DFT calculations presented in this work clarified the key roles of the electron-deficient lattice oxygen $\left(\mathrm{O}_{\text {lat }}\right)$ and flexible $\mathrm{CeO}_{2}$ matrix controlled by valence and ionic radius of 
heterocations. Additionally, the performance of doped $\mathrm{CeO}_{2}$ was investigated experimentally using $\mathrm{NH}_{3}$ synthesis in the electric field as a model reaction. Results confirmed close agreement with those obtained from DFT studies.

\section{Method}

\subsection{Electronic structure calculations}

We conducted DFT calculations for $\mathrm{CeO}_{2}$ (111) surfaces with dopants, as described in our earlier report. ${ }^{20}$ We have already confirmed the validity of the calculation conditions and models. We used the Vienna $a b$ initio simulation program (VASP 5.4.4) for all DFT calculations. ${ }^{28-31}$ The core-valence interaction was described using the projector augmented wave (PAW) method. ${ }^{32}$ The valence electrons were expanded with the cutoff energy of $400 \mathrm{eV}$. We summarized the configurations of valence electrons in Table S1 (ESI $\dagger$ ). The generalized gradient approximation (GGA) of Perdew-Burke-Ernzerhof (PBE) was applied to express the exchange correlation. ${ }^{33}$ Spin was polarized for all simulations. We used $k$-point mesh with Gaussian smearing for $\mathrm{CeO}_{2}$ bulk $(5 \times 5 \times 5)$ and slab $(1 \times 1 \times 1)$ models. ${ }^{34}$ The energy convergence was checked with $10^{-5} \mathrm{eV}$ criteria. The van der Waals (vdW) dispersion forces were applied using the DFT-D3 method described by Grimme. ${ }^{35}$ The $\mathrm{DFT}+U$ method was used for considering the on-site Coulomb repulsion of Ce $4 f$ orbitals. The $U$ value was set to $5.0 \mathrm{eV}^{20,36-43}$

\subsection{Computational models}

We used the $\mathrm{CeO}_{2}(111)$ surface as a repeated $(4 \times 4)$ supercell containing O-Ce-O tri-layers. The lattice constant of the DFToptimized $\mathrm{CeO}_{2}$ bulk structure $(5.43 \AA$ ) was applied to that of slab models. Each slab was separated in the $z$ direction with $20 \AA$ vacuum gap. Only the bottom $\mathrm{O}-\mathrm{Ce}-\mathrm{O}$ layer was fixed during geometry optimizations without other notations. Two $\mathrm{Ce}$ at the uppermost surface were replaced by divalent $(\mathrm{Ca}, \mathrm{Sr}$, $\mathrm{Ba}$ ), trivalent ( $\mathrm{Al}, \mathrm{Ga}, \mathrm{Sc}, \mathrm{Y}, \mathrm{La})$, and quadrivalent ( $\mathrm{Hf}, \mathrm{Zr}$ ) cations for expressing the doped surfaces. Gaseous $\mathrm{H}_{2}$ was placed in a $10 \times 10 \times 10 \AA$ cubic box. Calculations were performed at $\Gamma$ point. All calculation models were depicted for observation using VESTA. ${ }^{44} \mathrm{H}$ atoms were placed at the top of surface oxygen of $\mathrm{Ce}_{1-x} \mathrm{M}_{x} \mathrm{O}_{2-\delta}(111)$, and the geometry was optimized. The most stable $\mathrm{H}$ atom adsorption structures on each surface are shown in Fig. S1 (ESI $\dagger$ ). The detail of the calculation flows is shown in Section 3.1.

\subsection{Preparation of Fe-supported $\mathrm{CeO}_{2}$-based materials}

Using a complex polymerization method, $\mathrm{CeO}_{2}$ and $\mathrm{Ce}_{0.9} \mathrm{M}_{0.1}$ $\mathrm{O}_{2-\delta}(\mathrm{M}: \mathrm{Sr}, \mathrm{Al}, \mathrm{Y}$, and $\mathrm{Zr}$ ) were synthesized. First, citric acid monohydrate (Kanto Chemical Co. Inc.) and ethylene glycol (Kanto Chemical Co. Inc.) were dissolved in distilled water. Then, stoichiometric amounts of precursors (Kanto Chemical Co. Inc.) were added. The precursors are presented in Table S2 (ESI $\dagger$ ). The mixture was stirred at $343 \mathrm{~K}$ overnight. Subsequently, the obtained solution was dried and crushed. Finally, the obtained powder was calcined at $773 \mathrm{~K}$ for $5 \mathrm{~h}$ with a ramping rate of $5 \mathrm{~K} \mathrm{~min}^{-1}$.

5 wt $\%$ of Fe was loaded over synthesized $\mathrm{CeO}_{2}$-based materials using a liquid-phase reduction method as reported elsewhere. ${ }^{45}$ First, $\mathrm{Fe}\left(\mathrm{NO}_{3}\right)_{3} \cdot 9 \mathrm{H}_{2} \mathrm{O}$ (Kanto Chemical Co. Inc.) was poured into distilled water. The support was dispersed in the obtained Fe aqueous solution by stirring for $1 \mathrm{~h}$. Subsequently, the solution was heated at $393 \mathrm{~K}$ for $1 \mathrm{~h}$ under Ar flow. Then, $10 \% \mathrm{~N}_{2} \mathrm{H}_{4}$ solution (Fujifilm Wako Pure Chemical Corp.) was added dropwise. The slurry was stirred at $393 \mathrm{~K}$ for $1 \mathrm{~h}$ under Ar flow. The slurry was filtered. The obtained cake was dried at $393 \mathrm{~K}$ overnight.

\subsection{Activity tests}

$\mathrm{NH}_{3}$ synthesis rates were examined using a fixed bed flow type reactor equipped with a quartz tube under $0.1 \mathrm{MPa} .5 \mathrm{wt} \% \mathrm{Fe} /$ support was sieved into $355-500 \mu \mathrm{m}$ granules. Then $0.1 \mathrm{~g}$ of them were charged into the reactor. For application of the electric field, two stainless steel (SUS 304) rods were attached on the catalyst bed. Then $6 \mathrm{~mA}$ direct current was applied using a power supply device. The temperature of the catalyst bed when heated with Joule heat was measured directly using a thermocouple attached on the bottom of the catalyst bed. Applied currents and response voltages were detected using a digital phosphor oscilloscope (TDS 2001C; Tektronix Inc.). A schematic image of the reactor is portrayed in Fig. S2 (ESI $\dagger$ ). The activities were measured under $\mathrm{N}_{2}: \mathrm{H}_{2}=1: 3$ (total flow 240 SCCM) at room temperature. Before the activity tests, prereduction was conducted at $773 \mathrm{~K}$ for $1 \mathrm{~h}$ under reaction conditions. The produced $\mathrm{NH}_{3}$ was dissolved into distilled water and was quantified using an ion chromatograph (IC-2001; Tosoh Corp.).

\subsection{X-ray photoelectron spectroscopy (XPS)}

XPS measurements were performed using a Versa Probe II (Ulvac-Phi Inc.) with $\mathrm{Al} \mathrm{K} \alpha$ as the X-ray source. The obtained binding energies were calibrated using $\mathrm{C} 1 s$ assigned to $\mathrm{C}-\mathrm{H}$ or $\mathrm{C}-\mathrm{C}(284.8 \mathrm{eV})$. Samples $\left(\mathrm{CeO}_{2}\right.$ and $\left.\mathrm{Ce}_{0.9} \mathrm{M}_{0.1} \mathrm{O}_{2-\delta}\right)$ were prereduced in the same manner as activity tests before XPS measurements. The pre-treated samples were transported to the measurement system without exposure to air using a transfer vessel. The peak fittings were conducted using the Proctor-Sherwood-Shirley method. ${ }^{46,47}$

\section{Results and discussion}

\subsection{Optimization of calculation models}

Governing factors of the adsorption energies over the doped surface were investigated using the calculation flows presented in Fig. 1. Here, surfaces of two types and hydrogen adsorption energies of three types were considered. First, structures of the $\mathrm{CeO}_{2}$ (111) slab were optimized. Then, a 'Fix surface' and 'Relax surface' with heterocations were constructed. All possible arrangements of heterocations were considered similarly to our earlier study. ${ }^{20}$ The arrangements which exhibited the 


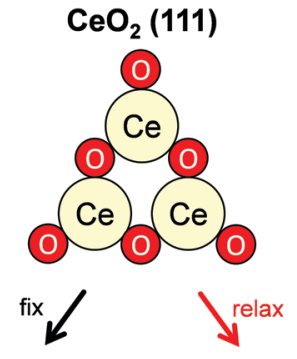

\section{Fix surface}

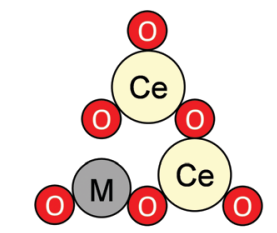

fix

Fix1 adsorption

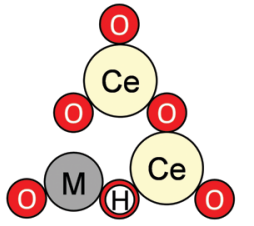

Fix2 adsorption

Relax surface

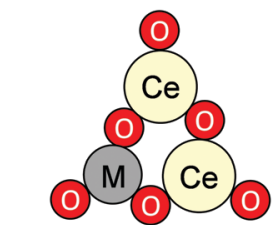

fix

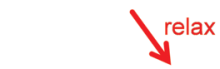

Relax adsorption

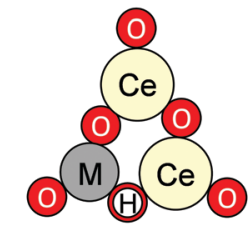

^

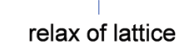

with doping

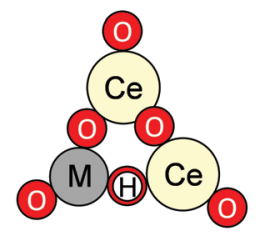

relax of lattice with adsorption

Fig. 1 Schematic image of the DFT calculation flows. Notations 'fix' and 'relax' near arrows denote whether the atom positions of surfaces were relaxed during geometry optimization. As for 'Fix surface', only heterocations were relaxed during geometry optimization. The $\mathrm{Ce}-\mathrm{O}$ matrix was relaxed for 'Relax surface'. 'Fix surface' was used for the calculations of 'Fix 1 adsorption'. Only the adsorbed $\mathrm{H}$ atoms were relaxed. The calculations of 'Fix 2 adsorption' and 'Relax adsorption' were conducted using 'Relax surface'. Regarding 'Fix 2 adsorption', only $\mathrm{H}$ atom was relaxed. The surfaces were optimized for the calculation of 'Relax adsorption'.

smallest total energies were applied to the next step. Fig. 2 portrays the obtained dopant distribution. Quadrivalent cations (Hf: $0.83 \AA, \mathrm{Zr}: 0.84 \AA$ ) and large cations with other valences (La: $1.16 \AA$, Sr: $1.26 \AA$, Ba: $1.42 \AA$ ) tend to separate from one another. Additionally, small divalent (Ca: $1.12 \AA$ ) or trivalent cations (Al: $0.54 \AA$, Ga: $0.62 \AA$, Sc: $0.87 \AA$, Y: $1.02 \AA$ ) favourably adjoin. The smaller the ionic radius of a heterocation, the more likely it is to cause lattice shrinkage on the $\mathrm{CeO}_{2}$ surface. To mitigate this shrinkage, small cations need to be placed next to each other. In contrast, heterocations with large ionic radii push away surrounding atoms. To relax this distortion, the cations with larger ionic radii must exist apart from each other. It was also empirically known that the solubility of heterocations depends on ionic radii. ${ }^{48}$ The heterocations with lower valences also cause lattice distortion because of the change in the number of bonds allowed by the cations. Hence, the valence also affects the distribution of heterocations. In the $\mathrm{CeO}_{2}$ matrix, Ce ions exist as quadrivalent cations. Therefore,

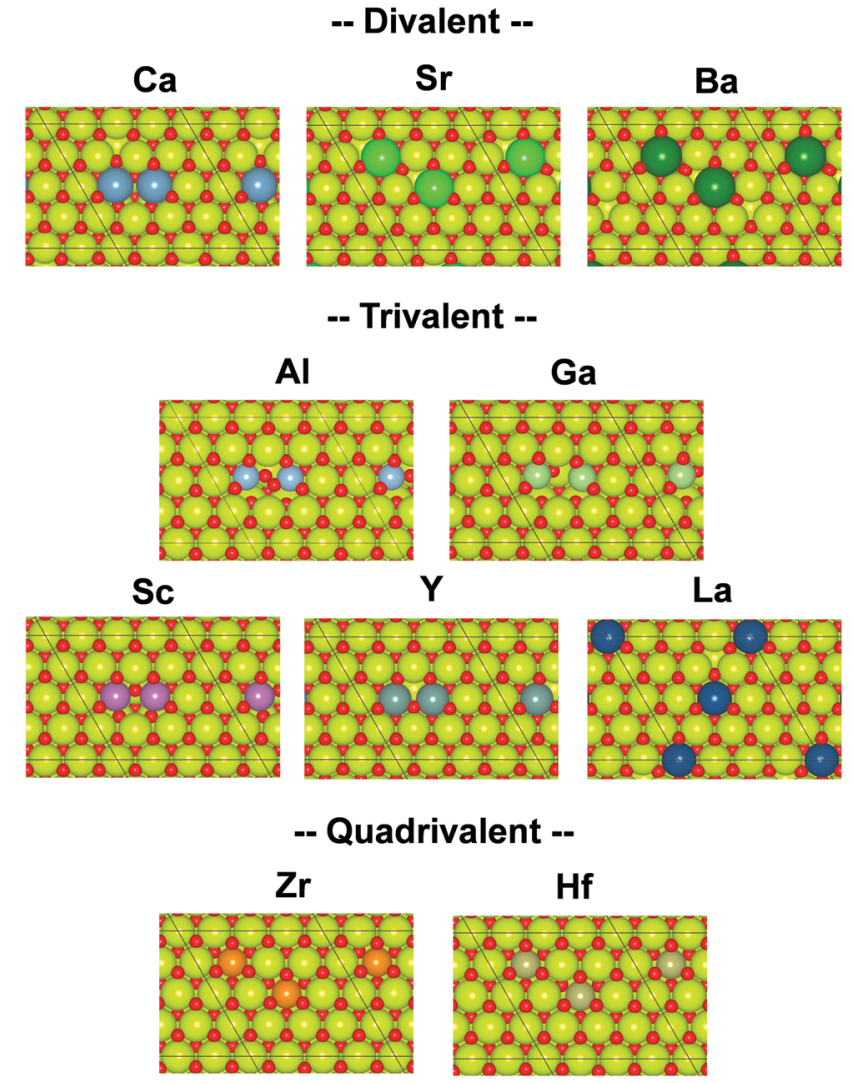

Fig. 2 Top view of the DFT-optimized heterocation-doped $\mathrm{CeO}_{2}(111)$ surface with oxygen vacancy for charge compensation ('Relax surface' in Fig. 1). Yellow denotes Ce. Red denotes oxygen. Others represent dopants.

as the next step, divalent or trivalent cation doping can be expected to induce voluntary oxygen vacancy formation. It is known that localized electron holes are formed on the lattice oxygen when metal oxides are doped with lower valence cations. $^{49-51}$ The formation of electron holes by doping with lower valent cations and the compensation of the holes by the formation of oxygen vacancies were elucidated in our previous works. ${ }^{20}$ We examined all arrangements of oxygen vacancy at the surface and sub-surface. The sites which show the smallest oxygen vacancy formation energies were taken over for the following calculations. The obtained oxygen vacancy formation energies are presented in Table S3 (ESI $\dagger$ ). Aside from Al-doping, the oxygen formation for charge compensation was an exothermic reaction. Peroxide $\left(\mathrm{O}_{2}{ }^{2-}\right)$ was specifically formed; it compensated the charge difference as for Al-doped $\mathrm{CeO}_{2}(111){ }^{20}$ The obtained surfaces are depicted in Fig. 2. Those surfaces are the structure of the 'Relax surface' presented in Fig. 1. As the next step, the 'Fix surface' was constructed. Here, two of Ce were replaced by heterocations and oxygen vacancies for charge compensation were arranged (peroxide was placed over $\mathrm{CeO}_{2}$ with $\mathrm{Al}$ ). Then, the dopant position was optimized solely, although the other atoms were fixed. Dopants and oxygen vacancy were arranged along with the 'Relax surface' presented in Fig. 1. The obtained models of the 'Fix surface' are shown in Fig. S3 (ESI $\dagger$ ). After that, $\mathrm{H}$ atom adsorptions of three types 
('Fix 1 adsorption', 'Fix 2 adsorption' and 'Relax adsorption') were investigated using the 'Fix surface' and 'Relax surface'. 'Fix surface' was applied to the calculations of 'Fix 1 adsorption'. Only the adsorbed $\mathrm{H}$ atoms were relaxed in this calculation. In addition, the calculations of 'Fix 2 adsorption' and 'Relax adsorption' were conducted over the 'Relax surface'. Regarding 'Fix 2 adsorption', only $\mathrm{H}$ atom was relaxed. The surfaces were optimized for the calculation of 'Relax adsorption'. Comparison between 'Fix 1 adsorption' and 'Fix 2 adsorption' shed light on the effects of lattice constraint caused by heterocation-doping. Furthermore, the difference between 'Fix 2 adsorption' and 'Relax adsorption' shows us doping effects on surface distortion along with $\mathrm{H}$ atom adsorption.

\subsection{Doping effects on $\mathrm{H}$ atom adsorption}

$\mathrm{H}$ atoms preferably adsorb at the surface oxygen of $\mathrm{CeO}_{2}$, where they exist as $\mathrm{H}^{+}{ }^{52}$ Adsorption at all surface oxygens was considered for all doping models. Fig. 3 presents box plots of adsorption energies. The expression of $E\left(\mathrm{H}_{\mathrm{ad}}\right)$ denotes adsorption energies of 'Relax adsorption', whereas $E\left(\mathrm{H}_{\mathrm{ad}}\right.$ fix 1$)$ and $E\left(\mathrm{H}_{\text {ad_fix }}\right)$, respectively, represent adsorption energies for 'Fix 1 adsorption' and 'Fix 2 adsorption'. Adsorption energies $\left(E_{\mathrm{ad}}\right)$ are calculated as eqn (1).

$$
E_{\text {ad }}=E(\text { slab with } \mathrm{H})-E(\text { slab without } \mathrm{H})-1 / 2 E\left(\mathrm{H}_{2}\right)
$$

Hereinafter, $E($ slab with $\mathrm{H})$ and $E($ slab without $\mathrm{H})$, respectively, denote energy values of the slab with and without adsorbed $\mathrm{H}$ atoms. $E\left(\mathrm{H}_{2}\right)$ represents the energy of gaseous $\mathrm{H}_{2}$. Hence, the energy of $\mathrm{H}-\mathrm{H}$ bond cleavage is included into the calculated $E_{\text {ad }}$. However, it is constant among all surfaces. Hence, the energy of $\mathrm{H}-\mathrm{H}$ bond cleavage does not affect the trends of adsorption energies. Boxes in Fig. 3 are colored along with dopant valences. Black plots show average adsorption values. The box arrangement is determined by the ionic radius of dopants. The DFT calculations elucidated the importance of ionic radius and valence. First, results in 'Fix 1 adsorption' (Fig. 3(a)) showed strong binding of $\mathrm{H}$ atoms over the divalentcation-doped surfaces. The second was trivalent-cation-doped surfaces. The third was quadrivalent. The electron donation from cations to adjacent $\mathrm{O}_{\text {lat }}$ decreases as the dopant valence becomes smaller when the dopants are placed forcibly into the metal oxide matrix suitable for higher valence cations. Accordingly, doping of lower valence cations results in the formation of Lewis acid sites. ${ }^{53,54}$ Then, the $\mathrm{H}$ atom was anchored strongly over the divalent-cation-doped surfaces. Lattice relaxation of two types evidently changed this trend. The former is the change from 'Fix 1 adsorption' to 'Fix 2 adsorption', and the latter is from 'Fix 2 adsorption' to 'Relax adsorption'. Smaller cation doping positively influences the $\mathrm{H}_{2}$ dissociative adsorption as for both 'Fix 2 adsorption' and 'Relax adsorption'. The first reason is the change of $\mathrm{O}_{\text {lat }}$ charge induced by lattice distortion after doping. The Ce valence after oxygen vacancy formation depends on the Ce-O bond length. ${ }^{55}$ Therefore, we can assume that $\mathrm{Ce}-\mathrm{O}$ bond expansion makes $\mathrm{O}_{\text {lat }}$ electron (a)
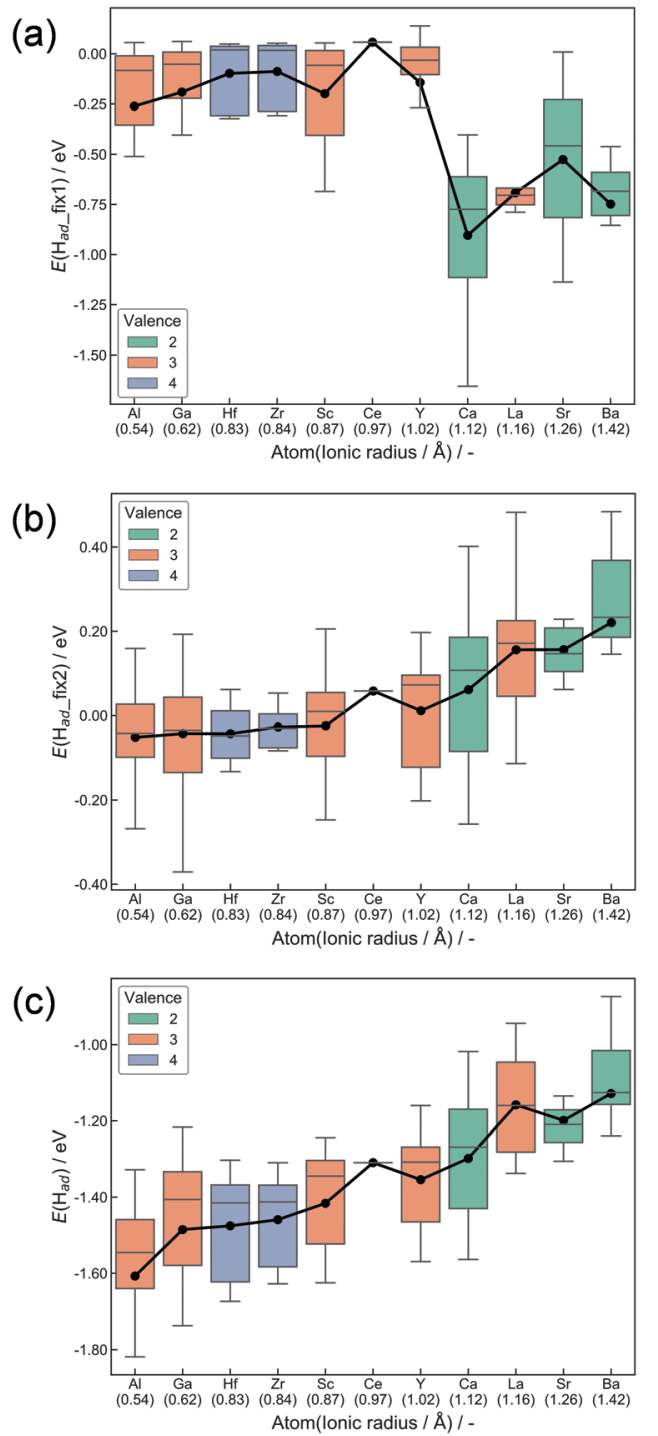

Fig. 3 Box plots for $\mathrm{H}_{2}$ dissociative adsorption energies. (a) 'Fix 1 adsorption', (b) 'Fix 2 adsorption' and (c) 'Relax adsorption'. The whisker length is set as 1.5 times of the interquartile range. Black plots show average values.

deficient. In contrast, the $\mathrm{Ce}-\mathrm{O}$ bond shrinkage makes the $\mathrm{O}_{\text {lat }}$ electron-rich. Large cations pushed the surrounding oxygen away, signaling shrinkage of the $\mathrm{Ce}-\mathrm{O}$ bond as summarized in Fig. S4 (ESI $\dagger$ ). As a result, the Lewis acidity derived from the difference of valence was moderated by the shrinkage. This moderation became smaller with the decrement in the dopant ionic radius. The change in the charge of $\mathrm{O}_{\text {lat }}$ by heterocationdoping and lattice distortion is summarized in Fig. S5-S10 (ESI $\dagger$ ). In terms of 'Relax adsorption', the smaller cation-doped surface became more favourable sites for $\mathrm{H}$ atom adsorption. The difference between 'Fix 2 adsorption' and 'Relax adsorption' exhibited effects of lattice distortion during $\mathrm{H}_{2}$ dissociative adsorption. A smaller cation-doped surface can take various relaxation patterns that are suitable for the acceptance of $\mathrm{H}$ atoms because of the spatial margin. In contrast, larger cations hinder the reconstruction of the surface along with 
adsorption. It means that the flexibility of the $\mathrm{CeO}_{2}$ matrix related to $\mathrm{H}$ atom adsorption is an important factor for controlling adsorption energies. For this reason, $\mathrm{H}_{2}$ dissociative adsorption over $\mathrm{CeO}_{2}$ is facilitated by doping with small ionic radii. The salient results of DFT calculations are presented below.

(1) Lower-valency dopant addition without lattice relaxation produces Lewis acid sites.

(2) The Lewis acidity above is alleviated by lattice relaxation when the ionic radius of dopants is large.

(3) The flexibility of the $\mathrm{CeO}_{2}$ matrix was enhanced by dopants with smaller ionic radius, leading to the strong adsorption of $\mathrm{H}$ atoms.

\subsection{Evaluation of $\mathrm{OH}$ amount using XPS}

The effect of doping on $\mathrm{H}_{2}$ dissociative adsorption was experimentally confirmed using XPS measurements. Fig. S14 and S15 $(\mathrm{ESI} \dagger)$ represent the $\mathrm{C} 1 \mathrm{~s}$ and $\mathrm{O}$ 1s spectrum of pre-reduced $\mathrm{CeO}_{2}$ and $\mathrm{Ce}_{0.9} \mathrm{M}_{0.1} \mathrm{O}_{2-\delta}(\mathrm{M}: \mathrm{Sr}, \mathrm{Al}, \mathrm{Y}$, and $\mathrm{Zr}$ ). Following the shape of differentiated spectra, the $\mathrm{C} 1 \mathrm{~s}$ and $\mathrm{O} 1 \mathrm{~s}$ spectra were decomposed into three and two components. The peaks around 285, 286 and $289 \mathrm{eV}$ in $\mathrm{C}$ 1s spectra can be, respectively, assigned to $\mathrm{C}-\mathrm{C}$ or $\mathrm{C}-\mathrm{H}, \mathrm{C}-\mathrm{O}$ and $\mathrm{O}-\mathrm{C}=\mathrm{O} .{ }^{56,57}$ Also, the peaks around 528 and $530 \mathrm{eV}$ in $\mathrm{O}$ 1s spectra can be assigned to $\mathrm{O}_{\text {lat }}$ and $\mathrm{O}-\mathrm{H}$ or $\mathrm{C}-\mathrm{O}$ or $\mathrm{O}-\mathrm{C}=\mathrm{O}$, respectively. ${ }^{57-59}$ Then, the $\mathrm{OH}$ ratio over each sample was calculated as follows:
DFT calculated energies was confirmed, indicating the validity of the DFT calculation results.

\subsection{Doping effects on the surface protonics and $\mathrm{NH}_{3}$ Synthesis in the electric field}

The former sections described that we could control the $\mathrm{H}$ atom adsorption over $\mathrm{CeO}_{2}$-based materials by the dopant valence and ionic radius. Therefore, we evaluated an actual effect of $\mathrm{H}_{2}$ dissociative adsorption energy on surface protonics and $\mathrm{NH}_{3}$ synthesis in the electric field. First, $6 \mathrm{~mA}$ constant direct current was applied to $5 \mathrm{wt} \% \mathrm{Fe} / \mathrm{CeO}_{2}$ and $5 \mathrm{wt} \% \mathrm{Fe} /$ $\mathrm{Ce}_{0.9} \mathrm{M}_{0.1} \mathrm{O}_{2-\delta}$ ( $\mathrm{M}: \mathrm{Sr}, \mathrm{Al}, \mathrm{Y}$ and $\mathrm{Zr}$ ). Consequently, the response voltages increased as the average $E\left(\mathrm{H}_{\mathrm{ad}}\right)$ decreased and encountered a limit at around $-1.30 \mathrm{eV}$ (Fig. 5). As reported elsewhere in the literature, $\mathrm{H}^{+}$migrates over the metal oxide surface under an $\mathrm{H}_{2}$ atmosphere. ${ }^{60}$ Presumably, the high response voltage under constant direct current corresponds to the lower $\mathrm{H}^{+}$ conductivity over the metal oxide surface. Considering results of both DFT calculations (Fig. 3(c)) and experimentation (Fig. 4 and 5), we concluded that the larger cation doping decreased the $\mathrm{H}^{+}$stability over the $\mathrm{CeO}_{2}$-based surface, leading to higher $\mathrm{H}^{+}$mobility. In contrast, the excess decrease in the $\mathrm{H}^{+}$stability causes a deficiency of $\mathrm{H}^{+}$. For that reason, the conductivity reached a limit at certain $\mathrm{H}$ atom adsorption energy even with high mobility of $\mathrm{H}^{+}$.

$$
\mathrm{OH} \text { ratio }=\frac{(\text { Area of } \mathrm{OH}+\mathrm{C}-\mathrm{O}+\mathrm{O}-\mathrm{C}=\mathrm{O} \text { in O 1s spectra })-\mathrm{RSF}_{\mathrm{O} 1 \mathrm{~s}} / \mathrm{RSF}_{\mathrm{C} 1 \mathrm{~s}}(\text { Area of } \mathrm{C}-\mathrm{O}+\mathrm{O}-\mathrm{C}=\mathrm{O} \text { in } \mathrm{C} 1 \mathrm{~s} \mathrm{spectra})}{\left(\text { Area of } \mathrm{O}_{\text {lat }} \text { in } \mathrm{O} \text { 1s spectra }\right)}
$$

Here, $\operatorname{RSF}_{x}(x=\mathrm{O} 1 \mathrm{~s}, \mathrm{C} 1 \mathrm{~s})$ denotes a relative sensitivity factor reported by Ulvac-Phi Inc. Fig. 4 shows the correlation between $\mathrm{OH}$ ratios from XPS measurements and averages of $E\left(\mathrm{H}_{\mathrm{ad}}\right)$ from DFT calculations using the 'Relax adsorption' model. Consequently, a clear correlation between experimental values and

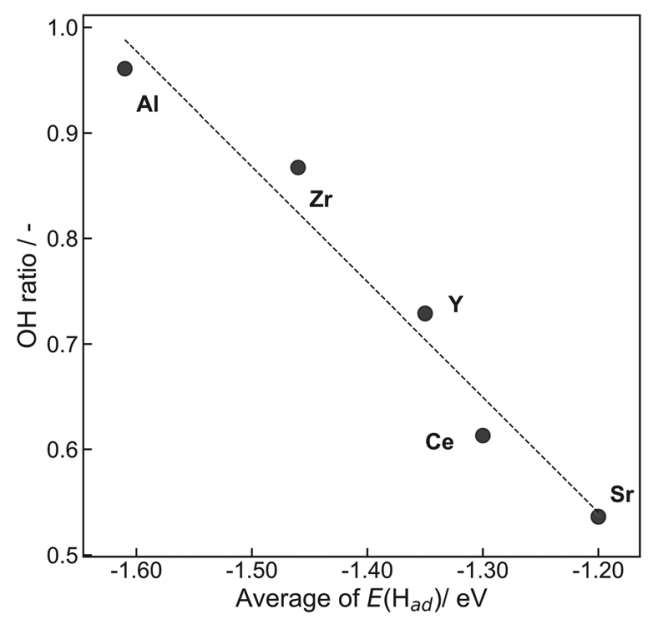

Fig. 4 Correlation between $\mathrm{OH}$ ratios obtained from XPS measurements and averages of $E\left(\mathrm{H}_{\mathrm{ad}}\right)$ obtained from DFT calculations using the 'Relax adsorption' model.
Next, we evaluated the heterocation-doping effect on catalytic reactions involving surface protonics. $\mathrm{NH}_{3}$ synthesis in the electric field was used as a model reaction. Enhancement of the $\mathrm{NH}_{3}$ synthesis rate in a low-temperature region using the electric field has been reported. ${ }^{11-15}$ We obtained knowledge

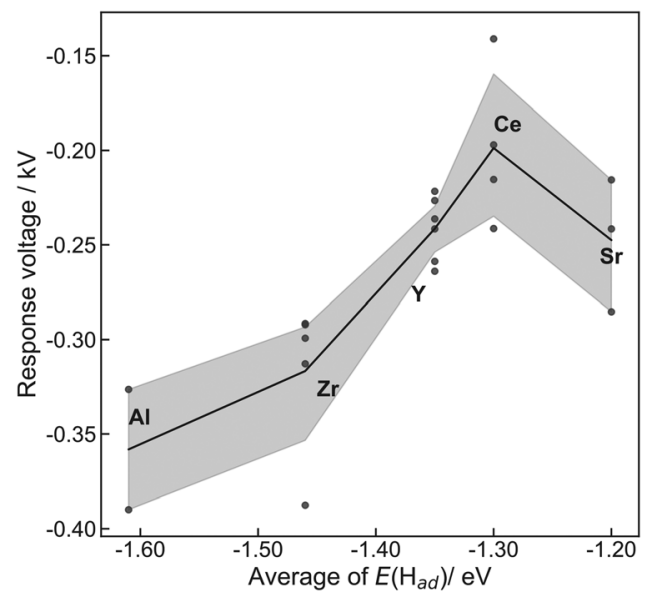

Fig. 5 Correlation between the average of $E\left(\mathrm{H}_{\mathrm{ad}}\right)$ obtained from DFT calculations using the 'Relax adsorption' model and response voltage during application of $6 \mathrm{~mA}$ direct current. Dark gray plots present all obtained data. The line graph shows average values. The gray area represents the $95 \%$ confidence interval. 
(a)

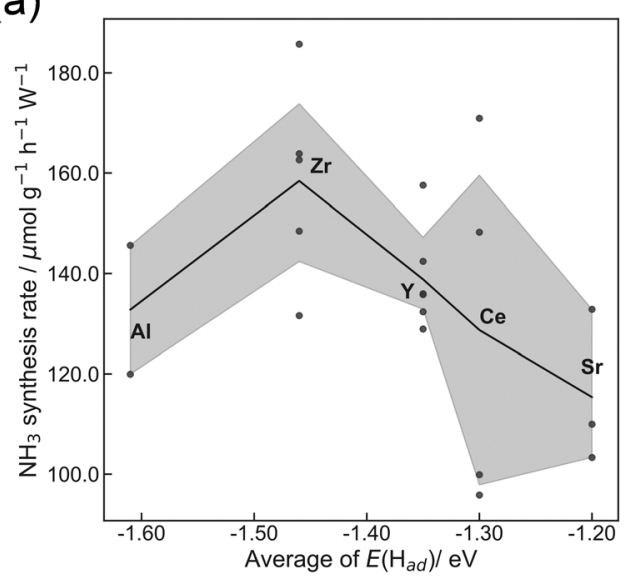

(b)

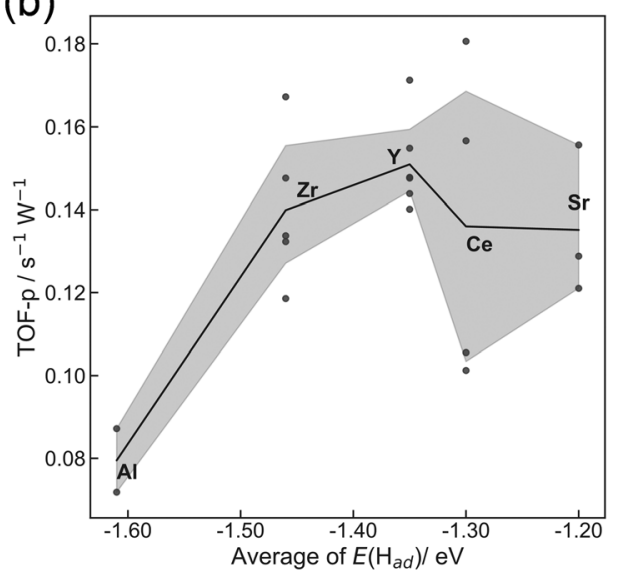

Fig. 6 Correlation between average of $E\left(\mathrm{H}_{a d}\right)$ obtained from DFT calculations using the 'Relax adsorption' model and (a) $\mathrm{NH}_{3}$ synthesis rate per power and (b) TOF-p per power in the electric field (6 mA). Dark gray plots show all obtained data. The line graph shows average values. The gray area represents the $95 \%$ confidence interval.

that $\mathrm{NH}_{3}$ synthesis in the electric field proceeds via the 'associative mechanism'. ${ }^{1}$ The $\mathrm{H}^{+}$over the support reacts with $\mathrm{N}_{2}$ over the loading metal. Therefore, the reaction rate depends strongly on the amount of metal atoms at the periphery. Moreover, $\mathrm{H}$ atom stability over supports is an important factor for controlling activity. ${ }^{13}$ The $\mathrm{NH}_{3}$ synthesis rate in the electric field can be a good indicator of heterocation-doping effects on $\mathrm{H}^{+}$stability. Fig. 6 presents the apparent $\mathrm{NH}_{3}$ synthesis rate and turnover frequency at the periphery (intrinsic activity at each active site, TOF-p) per unit of applied power. The TOF-p per unit of applied power was calculated as presented below. small ionic radius (e.g. Al) is optimal under such conditions. Conversely, the effect of the increase in $\mathrm{H}^{+}$ coverage becomes important when the $\mathrm{H}_{2}$ partial pressure is high, and the temperature is low. Therefore, heterocations with a large ionic radius (e.g. Ba) are the best dopants.

\section{Conclusions}

In summary, we clarified heterocation-doping effects on $\mathrm{H}_{2}$ dissociative adsorption over $\mathrm{CeO}_{2}(111)$ using DFT calculations.

$$
\mathrm{TOF}-\mathrm{p}\left[\mathrm{s}^{-1} \mathrm{~W}^{-1}\right]=\frac{\text { Number of mols of converted } \mathrm{N}_{2} \text { per unit time }\left[\mathrm{mols}^{-1}\right]}{\text { Number of metal atoms at perimeter }[\mathrm{mol}] \times \operatorname{Imposed} \text { current }[\mathrm{mA}] \times \text { Response voltage }[\mathrm{kV}]}
$$

Metal atoms at the perimeter were counted from the metal loading weight and mean particle sizes using the hemisphere approximation of the loading Fe particle structure. Volcano plots are presented for both apparent activity and intrinsic activity at each site (Fig. 6). This dependence is also explainable by $\mathrm{H}^{+}$stability over the support, as considered in $\mathrm{H}^{+}$conductivity (Fig. 5). When the $\mathrm{H}^{+}$binds too strongly over supports, the reactivity is limited, but excessively loose binding of $\mathrm{H}^{+}$engenders a decrement of reactants $\left(\mathrm{H}^{+}\right.$coverage over supports). This trade-off led to the volcano type relation between DFT calculated $E\left(\mathrm{H}_{\mathrm{ad}}\right)$ and $\mathrm{NH}_{3}$ synthesis rate in the electric field. In this manner, key roles of $\mathrm{H}^{+}$stability over $\mathrm{CeO}_{2}$-based materials on surface protonics and $\mathrm{NH}_{3}$ synthesis in the electric field were elucidated by virtue of guidance given by DFT calculations, as presented in Fig. 7. Based on our findings, the optimal dopant for $\mathrm{NH}_{3}$ synthesis in the electric field is expected to depend on temperature and $\mathrm{H}_{2}$ partial pressure as shown below. The effect of the decrease in $\mathrm{H}^{+}$coverage is more pronounced under low $\mathrm{H}_{2}$ partial pressure, and high temperature. Hence, the doping of heterocations with a
DFT-calculated adsorption energy of three types ('Fix 1 adsorption', 'Fix 2 adsorption' and 'Relax adsorption') shed light on the influence of dopant valence and ionic radius distinguishably. A Lewis acid site was formed with lower valence heterocation-doping ('Fix 1 adsorption'). However, $\mathrm{CeO}_{2}$ with lower valence dopants lost its acidity along with the lattice distortion caused by doping ('Fix 2 adsorption'). This tendency was evident for dopants with larger ionic radii. Eventually, the addition of dopants with a small ionic radius led to strong binding of $\mathrm{H}$ atoms ('Relax adsorption'). This strong adsorption resulted from the favourable lattice distortion during $\mathrm{H}_{2}$ dissociative adsorption. Furthermore, the important role of $\mathrm{H}$ atom stability on surface protonics and $\mathrm{NH}_{3}$ synthesis in the electric field was confirmed experimentally. The balance of $\mathrm{H}^{+}$reactivity (mobility) and $\mathrm{H}^{+}$coverage was fundamentally important for high $\mathrm{H}^{+}$conductivity and catalysis involving surface protonics. Those insights for $\mathrm{H}$ atom adsorption over $\mathrm{CeO}_{2}$-based materials are important not only for catalytic reactions involving hydrogen subtraction and migration 
(a)

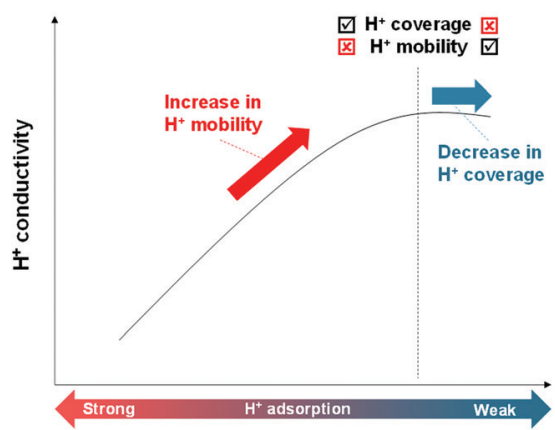

(b)

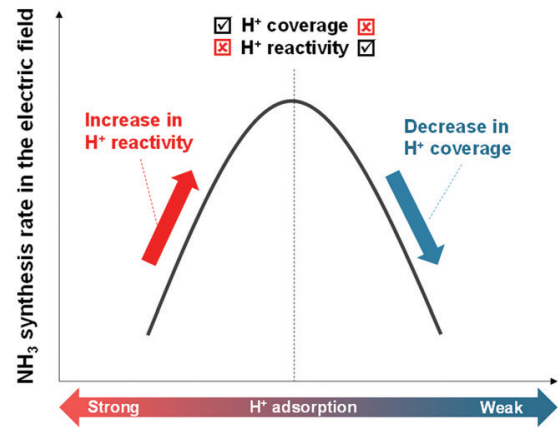

Fig. 7 Schematic image of the correlation among $\mathrm{H}^{+}$adsorption energy, and (a) $\mathrm{H}^{+}$conductivity or (b) $\mathrm{NH}_{3}$ synthesis rate in the electric field.

(hydrogen spillover and surface protonics), but also for electrochemical devices such as fuel cells and sensors.

\section{Conflicts of interest}

There are no conflicts to declare.

\section{Acknowledgements}

We gratefully appreciate support received from JST MIRAI and use of the supercomputer system at the Information Initiative Center at Hokkaido University.

\section{References}

1 K. Murakami and Y. Sekine, Phys. Chem. Chem. Phys., 2020, 22, 22852-22863.

2 L. Kuai, Z. Chen, S. Liu, E. Kan, N. Yu, Y. Ren, C. Fang, X. Li, Y. Li and B. Geng, Nat. Commun., 2020, 11, 48.

3 S. Campisi, C. E. Chan-Thaw, L. E. Chinhilla, A. Chutia, G. A. Botton, K. M. H. Mohammed, N. Dimitratos, P. P. Wells and A. Villa, ACS Catal., 2020, 10, 5483-5492.

4 X. Xue, J. Liu, D. Rao, S. Xu, W. Bing, B. Wang, S. He and M. Wei, Catal. Sci. Technol., 2017, 7, 650-657.

5 T. Franken, J. Terreni, A. Borgschulte and A. Heel, J. Catal., 2020, 382, 385-394.

6 S. K. Beaumont, S. Alayoglu, C. Specht, N. Kruse and G. A. Somorjai, Nano Lett., 2014, 14(8), 4792-4796.
7 Y. Guo, S. Mei, K. Yuan, D.-J. Wang, H.-C. Liu, C.-H. Yan and Y. W. Zhang, ACS Catal., 2018, 8, 6203-6215.

8 S. Wu, Y.-K. Peng, T.-Y. Chen, J. Mo, A. Large, I. McPherson, H.-L. Chou, I. Willkinson, F. Venturini, D. Grinter, P. F. Escorihuela, G. Held and S. C. E. Tsang, ACS Catal., 2020, 10, 5614-5622.

9 M. Torimoto, K. Murakami and Y. Sekine, Bull. Chem. Soc. Jpn., 2019, 92(10), 1785-1792.

10 Y. Sekine and R. Manabe, Faraday Discuss., DOI: 10.1039/ C9FD00129H.

11 R. Manabe, H. Nakatsubo, A. Gondo, K. Murakami, S. Ogo, H. Tsuneki, M. Ikeda, A. Ishikawa, H. Nakai and Y. Sekine, Chem. Sci., 2017, 8, 5434-5439.

12 K. Murakami, R. Manabe, H. Nakatsubo, T. Yabe, S. Ogo and Y. Sekine, Catal. Today, 2018, 303, 271-275.

13 K. Murakami, Y. Tanaka, S. Hayashi, R. Sakai, Y. Hisai, Y. Mizutani, A. Ishikawa, T. Higo, S. Ogo, J. G. Seo, H. Tsuneki, H. Nakai and Y. Sekine, J. Chem. Phys., 2019, 151, 064708.

14 K. Murakami, Y. Tanaka, R. Sakai, K. Toko, K. Ito, A. Ishikawa, T. Higo, T. Yabe, S. Ogo, M. Ikeda, H. Tsuneki, H. Nakai and Y. Sekine, Catal. Today, 2020, 351, 119-124.

15 K. Murakami, Y. Tanaka, R. Sakai, Y. Hisai, S. Hayashi, Y. Mizutani, T. Higo, S. Ogo, J. G. Seo, H. Tsuneki and Y. Sekine, Chem. Commun., 2020, 56, 3365-3368.

16 K. Takise, A. Sato, K. Murakami, S. Ogo, J. G. Seo, K. Imagawa, S. Kado and Y. Sekine, RSC Adv., 2019, 9, 5918-5924.

17 R. Manabe, S. Okada, R. Inagaki, K. Oshima, S. Ogo and Y. Sekine, Sci. Rep., 2016, 6, 38007.

18 A. Takahashi, R. Inagaki, M. Torimoto, Y. Hisai, T. Matsuda, Q. Ma, J. G. Seo, T. Higo, H. Tsuneki, S. Ogo, T. Norby and Y. Sekine, RSC Adv., 2020, 10, 14487-14492.

19 K. Toko, K. Ito, H. Saito, Y. Hosono, K. Murakami, S. Misaki, T. Higo, S. Ogo, H. Tsuneki, S. Maeda, K. Hashimoto, H. Nakai and Y. Sekine, J. Phys. Chem. C, 2020, 124(19), 10462-10469.

20 K. Murakami, S. Ogo, A. Ishikawa, Y. Takeno, T. Higo, H. Tsuneki, H. Nakai and Y. Sekine, J. Chem. Phys., 2020, 152, 014707.

21 W. Zhang, M. Pu and M. Lei, Langmuir, 2020, 36, 5891-5901.

22 M. D. Krcha, A. D. Mayernick and M. J. Janik, J. Catal., 2012, 293, 103-115.

23 J. J. Carey and M. Nolan, J. Catal., 2016, 6, 3544-3558.

24 T. Montini, M. Melchionna, M. Monai and P. Fornasiero, Chem. Rev., 2016, 116(10), 5987-6041.

25 M. Shirpour, G. Gregori, R. Merkle and J. Maier, Phys. Chem. Chem. Phys., 2011, 13, 937-940.

26 G. Gregori, M. Shirpour and J. Maier, Adv. Funct. Mater., 2013, 23, 5861-5867.

27 R. Manabe, S. Stub, T. Norby and Y. Sekine, Solid State Commun., 2018, 270, 45-49.

28 G. Kresse and J. Hafner, Phys. Rev. B: Condens. Matter Mater. Phys., 1993, 47, 558. 
29 G. Kresse and J. Hafner, Phys. Rev. B: Condens. Matter Mater. Phys., 1994, 49, 14251.

30 G. Kresse and J. Furthmüller, Comput. Mater. Sci., 1996, 6(1), 15-50.

31 G. Kresse and J. Furthmüller, Phys. Rev. B: Condens. Matter Mater. Phys., 1996, 54, 11169.

32 G. Kresse and D. Joubert, Phys. Rev. B: Condens. Matter Mater. Phys., 1999, 59, 1758.

33 J. P. Perdew, K. Burke and M. Ernzerhof, Phys. Rev. Lett., 1996, 77, 3865-3868.

34 H. J. Monkhorst and J. D. Pack, Phys. Rev. B: Condens. Matter Mater. Phys., 1976, 13, 5188-5192.

35 S. Grimme, J. Antony, S. Ehrlich and S. Krieg, J. Chem. Phys., 2010, 132, 154104.

36 M. D. Krcha, A. D. Mayernick and M. J. Janik, J. Catal., 2012, 293, 103-115.

37 H. T. Chen and J. G. Chang, J. Chem. Phys., 2010, 132, 214702.

38 M. Nolan, J. Chem. Phys., 2009, 130, 144702.

39 M. Nolan, J. Mater. Chem., 2011, 21, 9160-9168.

40 M. Nolan, J. Phys. Chem. C, 2011, 115, 6671-6681.

41 Z. X. Yang, G. X. Luo, Z. S. Lu and K. Hermansson, J. Chem. Phys., 2007, 127, 074704.

42 A. D. Mayernick and M. J. Janik, J. Phys. Chem. C, 2008, 112(38), 14955-14964.

43 M. B. Watkins, A. S. Foster and A. L. Shluger, J. Phys. Chem. C, 2007, 111(42), 15337-15341.

44 K. Momma and F. Izumi, J. Appl. Crystallogr., 2011, 44, 1272-1276.

45 R. Sakai, K. Murakami, Y. Mizutani, Y. Tanaka, S. Hayashi, A. Ishikawa, T. Higo, S. Ogo, H. Tsuneki, H. Nakai and Y. Sekine, ACS Omega, 2020, 5(12), 6846-6851.
46 D. A. Shirley, Phys. Rev. B: Condens. Matter Mater. Phys., 1972, 5(12), 4709.

47 A. Proctor and P. M. A. Sherwood, Anal. Chem., 1982, 54(1), 13-19.

48 D.-J. Kim, J. Am. Ceram. Soc., 1989, 72(8), 1415-1421.

49 M. Nolan and G. W. Watson, Surf. Sci., 2005, 586(1-3), 25-37.

50 M. Nolan and G. W. Watson, J. Chem. Phys., 2006, 126, 144701.

51 O. F. Schirmer, J. Phys.: Condens. Matter, 2006, 18, 667-704.

52 M. G. Melchor and N. López, J. Phys. Chem. C, 2014, 118, 10921-10926.

53 Z. Hu, B. Li, X. Y. Sun and H. Metiu, J. Phys. Chem. C, 2011, 115, 3065-3074.

54 E. W. McFarland and H. Metiu, Chem. Rev., 2013, 113, 4391-4427.

55 H.-Y. Li, H.-F. Wang, X.-Q. Gong, Y.-L. Guo, Y. Guo, G. Lu and P. Hu, Phys. Rev. B: Condens. Matter Mater. Phys., 2009, 79, 193401.

56 M. Mantel and J. P. Wightman, Surf. Interface Anal., 1994, 21, 595-605.

57 E. McCafferty and J. P. Wightman, Surf. Interface Anal., 1998, 26, 549-564.

58 J. T. Newberg, D. E. Starr, S. Yamamoto, S. Kaya, T. Kendelewicz, E. R. Mysak, S. Porsgaard, M. B. Salmeron, G. E. Brown Jr., A. Nilsson and H. Bluhm, Surf. Sci., 2011, 605, 89-94.

59 G. P. López, D. G. Castner and B. D. Ratner, Surf. Interface Anal., 1991, 17, 267-272.

60 Y. Hisai, K. Murakami, Y. Kamite, Q. Ma, E. Vøllestad, R. Manabe, T. Matsuda, S. Ogo, T. Norby and Y. Sekine, Chem. Commun., 2020, 56, 2699-2702. 